says in his paper that distension of the heart and stretching of the nerve elements in the cardiac wall cannot coexist with an increased arterial pressure, but I cannot see on what grounds this statement is made. In my paper on cardiac pain and angina pectoris I have compared the pain in the heart during angina to that which occurs in the bladder or colon when these are distended and trying in vain to empty themselves. And here I may note that a sharp distinction must be made between distension and dilatation, for in all these cases it is possible for the organ to remain of its normal size or be even smaller than normal, yet be extremely distended and both its contents and its muscular walls be under great pressure because these walls are contracting firmly on the contents of the viscus. On the other hand, all three organs may be dilated much above their normal size and may not be distended at all. As I have pointed out in the paper to which I have already referred the condition which causes intense pain in the colon and bladder is an attempt of the muscular walls to expel their contents against a resistance which they are unable to overcome. Judging by analogy I consider the cardiac pain in one form at least of angina pectoris to be due to the ineffectual attempts of the heart to empty itself in face of increased arterial pressure, though how far the pain is due to distension and how far to irritation of the sensory nerves in the heart by violent contraction of its muscular fibres I cannot say. Pain will occur in the colon and bladder without any patchy degeneration of their walls. Patchy degeneration of the heart will undoubtedly enfeeble it, will give rise to inability to empty itself in face of increased arterial pressure, and may thus produce the symptoms of angina pectoris. But unless it can be shown that angina occurs only when the heart has undergone patchy degeneration and does not occur when degeneration occurs evenly over the whole ventricle, Dr. Colbeck's hypothesis, ingenious as it is, cannot be regarded as proved. In favour of the correctness of my own opinion I may adduce the fact that it led me to employ an entirely new method of treatment-namely, the lowering of arterial pressure by the administration of nitrite of amyl. I first described this method in THE LANCET of July 27th, 1867, p. 97 , and the success of my plan of lowering the blood pressure either by this drug or by others which have a similar action has been conclusively proved by an experience of more than 35 years.

March 25th.

I am, Sirs, yours faithfully, LAUDER BRUNTON.

\section{THE QUARANTINE STATION AT MARSEILLES.}

To the Editors of THE LANCET.

SrRs, -As one of the passengers who landed at the island of Frioul from the Oroya on Jan. 10th last I would like to add a few words to those of your Paris correspondent in THE LANCET of March 21st, p. 844. I preface my remarks, and $I$ am sure all the others who were present would do the same, with an expression of profound sympathy with M. Tessier and his family in the loss which they have sustained. The death of the young man is undoubtedly due to the detention, under misrepresentation, at the lazaretto.

In addition to the defects which your correspondent notes and to the discomfort arising from the eternal mistral I particularly mention the sanitary arrangements : so disgusting were they that being a member of a profession which concerns itself with these matters, and finding no attendance, I frequently during the five days, myself, did housemaid's duty. One is bound to say that the food was good, but the place in which it was prepared was very dirty and was the common room of many undesirable persons. Of the minor discomforts and the want of the small necessities of life I do not speak; they were many and irritating, especially to the seven ladies concerned. I am sure that all present at Frioul, French, Hungarian, and English, agree with your correspondent that the quarantine station at Marseilles is a disgrace to France. - I am, Sirs, yours faithfully,

THEO. MOORE, A.R.I.B.A.

Caroline-place, Mecklenburgh-square, W.C. March 30th, 1903.

\section{THE TEETH OF THE PITCAIRN ISLANDERS.}

\section{To the Editors of THE LANCET.}

SIRS,-In November, 1901, the daily and medical papers made comments on an interesting minute (February, 1899, and August, 1901) published by the Admiralty concerning the Pitcairn islanders. My attention was directed more especially to the details mentioned concerning the state of decay of the upper front teeth (permanent) so noticeable in many of the islanders. I wrote to the Lords of the Admiralty asking whether they would allow a series of questions concerning this feature of the teeth to be given to the medical officer of the first man-of-war which might visit Pitcairn Island. Their lordships at once agreed to this. Mr. C. S. Tomes very kindly revised a list of questions which I drew out and we then submitted the following questions (see inclosure No. 1) to be given to the medical officer of His Majesty's ship that might visit the island. The original papers were given to H.M.S. Condor, which vessel unfortunately was lost. Thanks to the care of the Admiralty a further copy of our questions was sent out and the following interesting communication (see inclosures Nos. 2 and 3) has been received which may be of interest to your readers.

I am, Sirs, yours faithfully.

J. KINGSTON BARTON, M.R.C.P. Lond.

London, March 29th, 1903.

[INCLOSURE No. 1.]

Questions.

The loss of front teeth has been noted by two independent observers and among other speculative causes it has been attributed to given whereon to form any opinion.

General.

1.-What proportion of the population are affected in this way ?

2.-Is there any difference î the sexes in this respect

3.-Are the back teeth also bad in the persons thus affected, or has some cause acted on the front teeth alone

4.-Would you say that the teeth had decayed and broken off, or are they worn away?

\section{Family.}

5.--Do the families affected differ in general physique from those which are not

6.-Are these families of European type as regards hair, features, de. or do they show indications of admixture with Polynesian blood? Specific.

7.-Can you learn of any habits-such as, for example, betel-nut chewing-which might infuence the teeth ?

8.- Or do they make any unusual use of their teeth in any of their bandicrafts ?

9.-Ask, in cases where the teeth are much decayed, if as an infant the child was breast fed for the usual period (six to nine months). If not, what food was given?

10.-Have you observed Hutchinson's teeth or any other marks of inherited syphilis among them?

11.-Would you say that the mental dulness noted as somewhat characteristic of the population is especially conspicuous in the persons having bad teeth?

Nov. 20th, 1901.

\section{(Signed) C. S. Tomes.}

(Signed)

To Commander C. H. Umfreville, H.M.S. Shearwater, Pacific Station, H.M. Ship Shearwater, at sea. 17th January, 1903. SIR,-On landing at Pitcairn Island with you on 10th January, 1903. I proceeded in pursuance of orders received to inquire into the alleged loss of the front teeth of the upper jaw amongst the inhabitants of this island. On the way from the landing place to the settlement and going through the settlement I met many of the inhabitants and and going through the settlement I met many of the inhabitants and
was very much struck by the fact that many of them were minus the was very much struck by the
front teeth of the upper jaw.

I carried out my inquiries concerning this peculiar phenomenon on the lines suggested by Mr. Tomes and Mr. J. Kingston Barton in their letter to the Secretary of the Admiralty of 20th November, 1901. The total population of the island is 153. This number is thus made upmales 74, of whom 27 are married; females, 79. Mr. Christian very kindly collected together a number of the inhabitants for me to examine. There were present 36 in all. These 36 were a very representative gathering, as there were 14 adult males, 10 adult females, seven male children, and five female children present.

Out of this number, six men, three women, four male children. and three female children showed the remarkable loss of front teeth. From these figures one may say that 50 per cent. of the people are affected and that there is practically no difference in the sexes. In all these cases, and especially in the younger people, the remainder of the teeth -i.e., the back teeth of the upper jaw and all the teethi of the lower jaw-were quite sound, in fact remarkably good. Most of the islanders had excellent teeth, barring the deficiency of the front in some cases. The incisors are apparently the only teeth affected in this peculiar manner-ats are apparently the only teeth affected in this peculiar MaCoy's testimony bears me out in case in the people I saw and Mr. McCoy's testimony bears me out in this statement. These teeth break
off owing to caries which sets in in childhood. Mr. McCoy informed off owing to caries which sets in in childhood. Mr. McCoy informed me that this decay commences soon after the permanent teeth are established and usually first attacks one of the middle incisors. One of the children I saw was thus affected. The other incisors soon become earious and break off close to the gums. As a rule Mr. McCoy extracts the stumps. Apparently if the teeth in childhood escape the peculiar form of caries they are not thus attacked in later life. Mr. McCoy also informed me that this dental trouble made its appearance for the first time amongst the fourth generation of islanders and certainly phenomenon. He says the children are more troubled in this way now phenomenon. He says the children are

The The children of Mr. Colfin, who has been 22 years on the island, are not affected, whereas the children of Mr. Warren who settled on Pitcairn Island in 1864 were affected. Both Mr. Coffin and Mr. Warre differ in no way, physique or otherwise, from the remainder of the 
inbabitants-in fact, I think most of the families have some members who exhibit these caries. The islanders generally have the Polynesian type of countenance-some more than others-but all types are equally troubled with their teeth.

The class of food eaten by the islanders does not, I think, in any way account for this early decay of teeth. The people mostly live on fruit which is abundant and consists of oranges, pineapples, figs, bananas, \&c. The only flesh meats they have are goats and fowls. They do not chew betel-nut or put their teeth to any extraordinary use. I saw no signs of syphilis in any of the cases I examined. In fact, I was struck by their remarkably healthy appearance. Some of the inhabitants do not appear to be very bright or over intelligent, but this may have been due to shyness before strangers. They do not show any marked signs of degeneration. The children are always breast fed by their mothers and are weaned at the usual time. I tested a sample of the drinking water and found it to be of excellent quality and free from all impurities. It contained no lime salts.

Appended are short answers to the direct questions asked by $\mathrm{Mr}$. C. S. Tomes and Mr. J. Kingston Barton.

$$
\text { I am, Sirs, yours faithfully, }
$$

(Signed) B. ScRIBNer, Surgeon.

[INCLOSURE No. 3.]

ANswers to Questions in ADMiralty LeTter of 20TH November,

1.-50 per cent. General.

3.- Some cause has acted on front teeth alone.

4.-Decayed and broken off. never worn away.

$$
\text { Family. }
$$

6.-No. Distinctly Polynesian.

7. $-\mathrm{No}$ Specific.

9.-Breast fed.

10. -No.

(Signed) R. B. ScRIbNER, Surgeon, R.N.

\section{THE MAKING OF POST-MORTEM EXA- MINATIONS BY GENERAL PRACTITIONERS. \\ To the Editors of THE LANCET.}

Sirs,-I feel sure that many medical men will fully agree with Dr. H. H. Littlejohn's remarks on the above subject published in THE LANCET of March 28th, p. 862 . The mere fact that it is possible to obtain diplomas in medicine and surgery without having even been present at a post-mortem examination is sufficient to throw a doubt on the reliability of such examinations when made without skilled assistance. In addition to this I consider that it is work from which a general practitioner would be much better relieved seeing that he may have to go straight from a post-mortem examination to a confinement, or a compound fracture.

I am, Sirs, yours faithfully,

EDwARD H. SwEet, B.A. Oxon., M.R.C.S. Eng., L. R.C.P. Lond.

Uckfield, March 30th, 1903.

\section{THEORIES OF IMMUNITY.}

To the Editors of THE LANCET.

SIRs,-It seems to me that purely imaginary theories like that of Ehrlich are of use only if they simplify the facts which have been ascertained. The subject of immunity is one of the utmost importance and we are already in possession of many important tacts in regard to it. If, therefore, Ehrlich's theory systematised these so as to give some insight into the guiding principles, so as to make the connexion between the different facts evident, so as to guide to the discovery of new facts, we might excuse its tangles of fantastic figures and erudite equations. But does it do any of these things? Dr. A. S. F. Grünbaum's explanations of Ehrlich's theories occupy your columns to-day. He tells us that a toxin molecule contains $H+T+X$. I can quite believe it. My acquaintance with organic chemistry would have led me to expect much more of it. But what is the use of all these cytophiles and haptophores? I may be stupid, but I cannot see it. The explanatory figures might, indeed, suggest new ideas to the designers of new carpets or wall-papers, but they do not to my mind convey a particle of useful information to a medical practitioner who wants to know enough of the processes of disease to be able to combat them.

I am, Sirs, yours faithfully,

Welbeck-street, W., March 27th, 1903. HUGH WoODs.

\section{A DISCLAIMER AND A WARNING.}

\section{To the Editors of THE LANCET.}

SIRS, - I am informed that a man of the name of "Dr. East" (or some similarly sounding name) is calling on medical men in Brighton describing himself as "Dr. Crocker's assistant" and trying to sell copies of my Atlas of Diseases of the Skin. I write to say that I know nothing of this person who is making this unauthorised use of my name and, except at the hospital, have no assistant. I may add that the Atlas is the property of the publisher and my only interest is a small royalty on each copy sold.

I am, Sirs, yours faithfully,

Harley-street, W., March 30th, 1903. H. RADCLIFFE CROCKER.

P.S.-I have since been informed that the man's name is Heath.

\section{THE RYE AND WOOLWICH ELECTIONS. To the Editors of THE LANCET.}

SIRs,-I am obliged to you for permitting me to rectify a mistake which some of the daily papers fell into in reporting what I said about these elections at our recent conference. In referring to them I mentioned that the anti-vaccinists in both constituencies had assisted the winning members : in the case of Mr. Will Crooks because he was an anti-vaccinist and in the case of Dr. Hutchinson because he was an anti. compulsionist. As we are fighting against compulsion we can conscientiously vote for a candidate who is opposed to the present law, which inflicts fines of $20 \mathrm{~s}$. and custs for the misdemeanour of taking the advice of a qualified medical man if he advises that a child should not be vaccinated.

Edgbaston, March 31st, 1903. I am, Sirs, yours faithfully,

** The Times and other responsible journals reported General Phelps as claiming Dr. Hutchinson as an opponent to vaccination. General Phelps should have written to these newspapers to rectify the widespread mis-statement without waiting until his attention was called to it by us.-ED. L.

\section{WANTED-A NEW ORDER OF NURSES. \\ To the Editors of THE LANCET.}

SIRs,-A question which has often suggested itself to me and to others is this. At present there are, I suppose, but three kinds of nurses available in a case of sudden illnessviz., (1) the institution nurse at $£ 22 s$. a week; (2) the ordinary occasional private nurse, generally a comparative amateur ; and (3) the infirmary visiting nurse. But it is apparent that these three alternatives cover only half the ground. In suburban London alone there must be thousands -scores of thousands- of households where the needs are not answered by any one of the three. I mean especially the households where no servant is kept-a kind of household getting very rapidly more numerous as servants get scarcer and the already appalling bill for rent and rates gets larger. In such families there are frequently both too little of poverty and too much of refinement either to justify or to make possible the infirmary nurse. The institution nurse would not go (even were the expense smaller) because the institution nurse is supplied on the understanding that she receives domestic attendance and does nothing but nurse the patient. The attendance would not be forthcoming and hence, as I say, she would not go. There remains only the private nurse. Some of these are most excellent people, but when driven into a corner in an emergency the medical man no less than the family may discover that they do not know of a private nurse who is disengaged. Moreover, there is a growing prejudice in favour of more science than these nurses ordinarily possess. What I submit to be necessary and urgent is this, some institution on a large scale whence, at any time of day or night, could be got for a guinea a week a nurse who would undertake not only the bare attendance on the patient, but such additional work as the preparation of her own and the patient's food, leaving any rough work to, let us say, a charwoman. Surely there must be plenty of women skilled in nursing who would not despise an opportunity of this kind? It would be infinitely better, too, for a medical man to find a practical scientific nurse at a bedside to whom he could give his directions rather than some unskilled amateur. As to the need, it is simply a crying one. It must be borne in mind that the neighbourliness which is assumed 